\title{
Modified Direct Torque Control using Algorithm Control of Stator Flux Estimation and Space Vector Modulation Based on Fuzzy Logic Control for Achieving High Performance from Induction Motors
}

\author{
Hassan Farhan Rashag ${ }^{\dagger *}$, S. P. Koh ${ }^{*}$, Ahmed N. Abdalla**, \\ Nadia M. L. Tan ${ }^{* * *}$, and K. H. Chong* \\ $\dot{\dagger}^{*}$ Dept. of Electronics and Communication Engineering, Universiti Tenaga Nasional, Selangor, Malaysia \\ ${ }^{* *}$ Faculty of Electrical and Electronic Engineering, University Malaysia Pahang, Pekan, Malaysia \\ ${ }^{* * *}$ Dept. of Electrical Power Engineering, Universiti Tenaga Nasional, Selangor, Malaysia
}

\begin{abstract}
Direct torque control based on space vector modulation (SVM-DTC) protects the DTC transient merits. Furthermore, it creates better quality steady-state performance in a wide speed range. The modified method of DTC using SVM improves the electrical magnitudes of asynchronous machines, such as minimizing the stator current distortions, the stator flux with electromagnetic torque without ripple, the fast response of the rotor speed, and the constant switching frequency. In this paper, the proposed method is based on two new control strategies for direct torque control with space vector modulation. First, fuzzy logic control is used instead of the PI torque and a PI flux controller to minimizing the torque error and to achieve a constant switching frequency. The voltages in the direct and quadratic reference frame $\left(V_{d}, V_{q}\right)$ are achieved by fuzzy logic control. In this scheme, the switching capability of the inverter is fully utilized, which improves the system performance. Second, the close loop of stator flux estimation based on the voltage model and a low pass filter is used to counteract the drawbacks in the open loop of the stator flux such as the problems saturation and dc drift. The response of this new control strategy is compared with DTC-SVM. The experimental and simulation results demonstrate that the proposed control topology outperforms the conventional DTC-SVM in terms of system robustness and eliminating the bad outcome of dc-offset.
\end{abstract}

Key words: Close loop of stator flux estimation, Direct torque control, Fuzzy logic control, Induction motor, Space vector modulation

\section{INTRODUCTION}

During the last decade, a lot of modifications in the classic Direct Torque Control scheme [1] have been made [2]. The purpose of these modifications was to develop the start up of the motor, the operation in overload conditions, and the low speed region. In addition, direct torque control minimizes the use of machine parameters [3]. As a result, it is less sensitive to

Manuscript received Nov. 2, 2012; revised Jan. 29, 2013

Recommended for publication by Associate Editor Sanjeet K. Dwivedi. †Corresponding Author: hassan_rashag@yahoo.com

Tel: +60-006-017-622-7499, Universiti Tenaga Nasional

*Dept. of Electronics and Communication Engineering, Universiti Tenaga Nasional, Malaysia

${ }^{* *}$ Faculty of Electrical and Electronic Engineering, University Malaysia Pahang, Malaysia

${ }^{* * *}$ Dept. of Electrical Power Engineering, Universiti Tenaga Nasional, Malaysia parameter variations. One of the disadvantages of conventional DTC is its high torque ripple [4]. Numerous techniques have been developed to diminish the torque ripple. The pulse duration of the output voltage vector is determined by the torque-ripple minimum condition. These improvements can significantly decrease the torque ripple, but they raise the complexity of the DTC algorithm. An alternative method to reduce the ripples is based on the space vector modulation (SVM) technique [5]. The algorithm control is based on the SVM technique to give a constant inverter switching frequency and a reduced flux with torque ripple. An adapted DTC scheme for induction machine drives with a fixed switching frequency and a low torque ripple was reported in [6]. A PI controller and SVM were used to reduce the torque ripples and to make the inverters have a constant frequency. A space vector is generated by two fuzzy logic controllers connected with 
hysteresis regulators. The first one is to control the flux and the other to control the torque. The use of fuzzy controllers permits a faster response and greater robustness. As an intelligent method, fuzzy control does not need an accurate mathematic model of the process to be controlled, and it uses the experience of people's knowledge to form its control rule base. A fuzzy logic controller is used to select the voltage vectors in a conventional DTC in [7]. For the duty ratio control method, a fuzzy logic controller is used to determine the duration of the output voltage vector at each sampling period [8]. These fuzzy logic controllers can provide good dynamic performance and robustness. A fuzzy adaptive controller was also used to reduce torque ripples [9]. In this method the duty ratio of the vectors was calculated based on fuzzy estimators and can effectively reduce the torque ripples. However, it cannot have a constant frequency. A significant improvement in the steady state performance was reported. Some of the different solutions proposed include DTC with SVM, different power converter topologies, such as multi-level inverters [10], [11], a matrix converter [12], sensor-less methods [13], [14], optimum stator flux estimators for high speed operation [15], [16], and artificial intelligence techniques, such as fuzzy logic and neuro-controllers [17]. Direct torque control consists of a pair of hysteresis comparators, torque and flux calculators, a lookup table, and a voltage-source inverter (VSI) [18]. However, major problems usually associated with this drive are a switching frequency that varies with the operating conditions, a high torque and flux ripples with current distortion.

The researchers in [19]-[21] proposed two fuzzy logic regulators to replace the classical PI regulators fuzzy space vector modulation direct torque control strategy for induction machines based on indirect matrix converters. On the other hand, [22]-[25] suggested two methods to improve the direct torque control performance. The first method is based on a GA for tuning the PI controller and the second method is based on the hybrid fuzzy sliding mode control theory. Some researchers have used a fuzzy PI controller in the speed control loop, where the hysteresis controller is substituted by a PI controller and the switching table is substituted by SVM [26], [27].

A sensor-less torque and speed control for the performance or induction motors based on the fuzzy logic technique is proposed in [28] in order to reduce torque and speed pulsations. Other researchers proposed DTC algorithms which are based on the application of space vector modulation (SVM) for prefixed time intervals [29], [30]. They presented Fuzzy logic controls with the speed-adaptive flux to enhance the performance of the system. Alternatively, the amplitude and angle of the stator flux is incorporated with the direct torque control for induction motor drives in [31] for determining the reference stator voltage vector in generating the pulse width modulation PWM output voltage for induction motors.

A multi layer neural network to emulate the traditional switching look up table method for the induction motors in direct torque control to obtained the optimal switching pattern was proposed in [32]. A novel control method with wavelet neural networks WNN is applied in [33] for the direct torque and flux control for induction motor drives. The WNN controller with the structure of the nonlinear auto regressive moving average based neural network NARMA is utilized as a speed controller to control the torque.

This paper proposes two control strategies for direct torque control with space vector modulation to achieve a high performance control system. First, two fuzzy logic controllers are used instead of PI torque and flux controllers to minimize the error of the torque, make the switching frequency constant and reduce the total harmonic distortions of the stator current. Second, a modified close loop integration algorithm of the stator flux estimation based on the voltage model, the stator current and a low pass filter is used. Simulation and experimental results demonstrate the validity of the proposed method by minimizing the torque error and the stator flux with a torque that is free of ripple at low speeds.

\section{MATHEMATICAL MODEL OF INDUCTION MOTORS}

The induction motor model can be expressed in the d-q fixed reference frame by Equations (1) to (6).

$$
\begin{gathered}
V_{s d q}=R_{s} i_{s d q}+\frac{d}{d t} \Psi_{s d q}-j w_{g} \Psi_{s d q} \\
0=R_{r} i_{r d q}+\frac{d}{d t} \Psi_{r d q}-j\left(w_{g}-w_{r}\right) \Psi_{r d q} \\
\Psi_{s d q}=l_{s} i_{s d q}+l_{m} i_{r d q} \\
\Psi_{r d q}=l_{r} i_{r d q}+l_{m} i_{s d q} \\
T_{e}=\frac{3 p}{2} L_{m}\left(\Psi_{s d} i_{s q}-\Psi_{s q} i_{s d}\right) \\
T_{e}-T_{l}=J \frac{d}{d t} w_{m}+B w_{m}
\end{gathered}
$$

where:

$w_{g}, w_{r}, w_{m}$ are the generic reference system, rotor electrical and rotor mechanical speeds. $R_{s}, R_{r}$ are the stator and rotor resistances. $L_{s}, L_{r}, L_{m}$ are the stator, rotor and mutual inductances. $\left(\Psi_{s d q}\right)$, is the stator flux in the d-q frame. $\left(\Psi_{r d q}\right)$, is rotor flux in the d-q frame. $\left(i_{s d q}, i_{r d q}\right)$ are the stator and rotor currents in the $\mathrm{d}-\mathrm{q}$ frame. $p$ is number of poles. $\left(T_{e}, T_{l}\right)$ are the motor and load torque. $(B, J)$ are the friction coefficient and inertia of the system. 


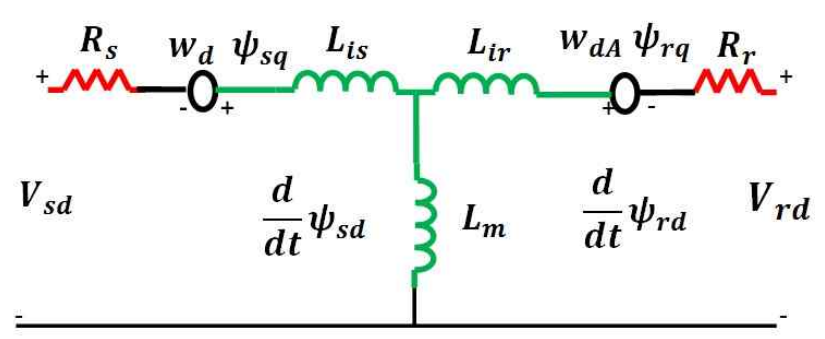

(a)

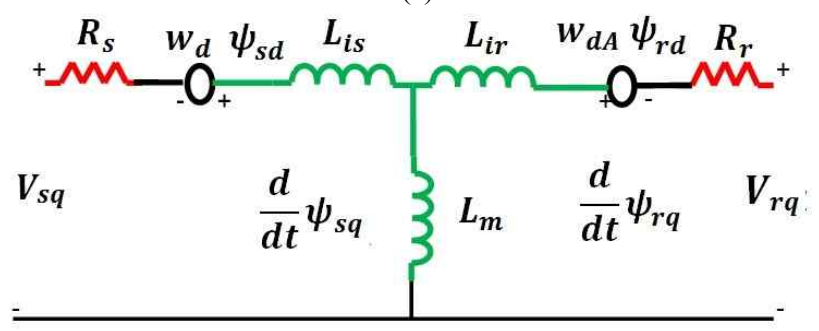

(b)

Fig. 1. Equivalent circuit of induction motor. (a) In d- reference frame. (b)In q- reference frame.

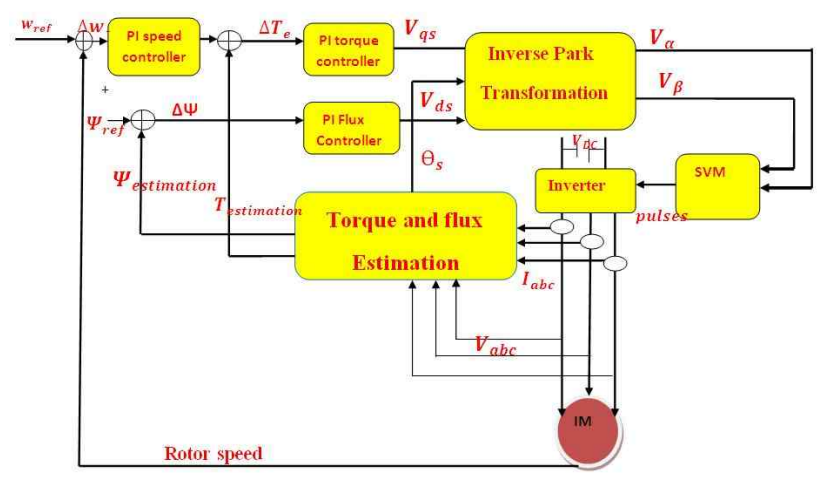

Fig. 2. Block diagram of direct torque control space vector Modulation.

\section{DiRECT TORQUE CONTROL WITH SPACE VECTOR MODULATION}

Direct Torque Control (DTC) is the first technology to control the "real" motor variables of torque and flux. In this method, the stator flux and the torque are controlled directly by selecting an appropriate inverter state. The principle of the conventional DTC system is its decoupled control of the stator flux and the electromagnetic torque. It also uses hysteresis control of stator flux error, torque error and stator flux position, and a switching table is included for selection of the voltage vectors feeding the induction motor by a voltage source inverter. The hysteresis comparator is replaced by PI torque and flux comparator while the switching table is replaced by space vector modulation, as shown in Fig.2, to improve the performance of the system and to achieve a constant switching frequency.

\section{Modified Close LoOP OF STATOR FluX ESTIMATION}

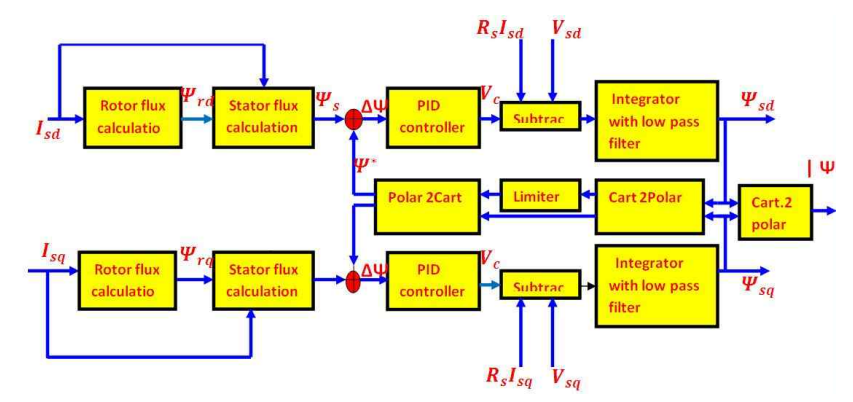

Fig. 3. Block diagram of stator flux estimation.

The control algorithm in the DTC-SVM methods are based on the averaged values and switching signals for the inverter which are calculated by the space vector modulator. DTC-SVM encounters drawbacks at low speeds which degrade the performance of the whole system. One of these drawbacks is the open loop integration of the stator flux estimation which causes a saturation problem and a dc drift. Stator flux estimation has an important effect on the performance of direct torque control. The proposed method to counteract this drawback is a close loop integration algorithm of the stator flux estimation which is based on the stator current, the voltage model, and a low pass filter, as shown in Fig.3.

The rotor flux is derived from the stator current in the direct reference frame and can be written by using the Laplace transform as:

$$
\Psi_{r d}(s)=\left[l_{m} I_{s d}(s)\right] /\left(1+T_{r} . s\right)
$$

Where $T_{r}=\frac{L_{r}}{R_{r}}$

The stator flux can be obtained from the stator current and the rotor flux as:

$$
\Psi_{s}(s)=\left(\frac{l_{m}}{l_{r}}\right) \Psi_{r d}(s)+\left(L_{s} L_{r}-L_{m}^{2}\right) I_{s d}(s)
$$

Substituting Eq.7 into (8) yields:

$$
\Psi_{s}(s)=\left(\frac{l_{m}}{l_{r}}\right)\left[l_{m} I_{s d}(s)\right] /\left(1+T_{r} . s\right)+\left(L_{s} L_{r}-L_{m}^{2}\right) I_{s d}(s)
$$

Voltage correction $(\mathrm{Vc})$ is derived from the difference between the stator flux through the PID controller as shown in Fig. 3 and is written as:

$$
\begin{gathered}
V_{\text {correct }}(s)=\Delta \Psi_{s}\left(K_{p}+\frac{K_{i}}{s}\right) \\
\Delta \Psi_{s}(s)=\Psi_{s}(s)-\Psi_{s}^{*}(s)
\end{gathered}
$$

The main purpose of the voltage correction is to correct the value of the stator flux and to compensate the error associated with pure integration for wide range of speeds.

The stator flux in the direct reference frame is given by: 


$$
\Psi_{s d}(s)=\frac{\left[V_{s d}-V_{c o r r e c t}-I_{s d} * R_{s}\right]}{\left(s+w_{c}\right)}\left[w_{c} \cdot T_{s}\right]
$$

where $\frac{1}{s+w_{c}}$ is the integrator with a low pass filter,

$\left(w_{c}\right)$ is the cutoff frequency and $\left(T_{s}\right)$ is the sampling time.

The aim of replacing the pure integrator with a low pass filter is to avoid the problems of saturation and integration drift due to the DC offsets present in the sensed currents or voltages. However, the LPF introduces phase and magnitude errors of the stator flux estimation which affect the selection of the voltages vector and electromagnetic torque response. It also deteriorates the performance of the DTC drive. To overcome these LPF problems, a close loop of the stator flux estimation is proposed. In this method, the stator flux is transformed to the amplitude and angle through a Cartesian to polar block. The magnitude of the stator flux is a dc signal and so is the limiter output. The flux magnitude and angle can be transformed back to Cartesian coordinates through a polar to Cartesian transform block, whose outputs are sinusoidal waveforms with a limited amplitude without distortion. This results in improved performance of the modified integrator. On the other hand, the limiter value should be equal to the stator flux reference. The cutoff frequency and the sampling time have been used in equation (12) to limit the phase difference between the actual stator flux and the estimated stator flux.

Assume that the cut off frequency is $(20 \mathrm{rad} / \mathrm{sec})$ and that the induction motor is running under the steady state.

By substituting equations (10) and (11) into equation (12), the stator flux in the direct reference frame can be derived as:

$$
\begin{gathered}
\Psi_{s d}(s)=\frac{\left[V_{s d}-I_{s d} R_{s}\right]-\left[\Psi_{s}(s)-\Psi_{s}^{*}(s)\right]\left(k_{p}+\frac{k_{i}}{s}\right)}{(s+20)}\left[w_{c}{ }^{*} T_{S}\right] \\
\Psi_{s d}(s)=\frac{s^{2} \Psi_{s d}-\left[\Psi_{s}(s)-\Psi_{s}^{*}(s)\right]\left(k_{p}+k_{i}\right)}{s(s+20)}\left[w_{c} * T_{S}\right]
\end{gathered}
$$

Where,

$$
\begin{aligned}
w_{c} T_{s} & =50 e^{-6} \times 20 \\
& \frac{\Psi_{s d}(s)}{\left[\Psi_{s}(s)-\Psi_{s}^{*}(s)\right]}=-\frac{\left(k_{p} s+k_{i}\right) T_{s} w_{c}}{\left(s^{2}+20 s\right)}
\end{aligned}
$$

The transfer function is

$$
\frac{\Psi_{s d}(s)}{\Delta \Psi_{s}}=-\frac{\left(k_{p} s+k_{i}\right)}{s} * \frac{T_{s} w_{c}}{(s+20)}
$$

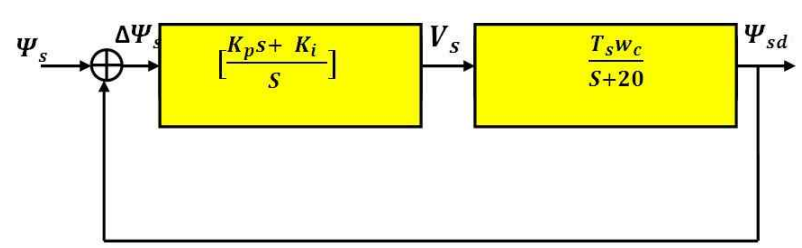

Fig. 4. Block diagram of close loop of stator flux estimation.

From equation (16), a block diagram of the close loop of the stator flux estimation in the direct axis is shown in Fig.4.

The parameters of the PID controller can be calculate either by using a discrete PID controller for auto tuning in Fig.4 till the desired output is obtained by Simulink MATLAB or by the following method.

From Fig.3, the stator flux is derived as:

$$
\begin{gathered}
\Psi_{S}^{*}(s)=\Psi_{s d} \cos \theta_{s} \\
\theta_{s}=w_{s} \cdot T_{s} \cong 0 \\
\Psi^{*}{ }_{S}(s)=\Psi_{s d}
\end{gathered}
$$

Substitute equation (19) into (15) as:

$$
\begin{gathered}
\frac{\Psi_{s d}(s)}{\left[\Psi_{s}(s)-\Psi_{s d}(s)\right]}=-\frac{\left(k_{p} s+k_{i}\right) T_{s} \cdot w_{c}}{\left(s^{2}+20 s\right)} \\
\frac{\Psi_{s d}(s)}{\Psi_{s}(s)}=-\frac{\left(k_{p} s+k_{i}\right) \cdot k}{s^{2}+s\left(20+k_{p} k\right)+k \cdot k_{i}}
\end{gathered}
$$

where $\left(k=w_{c} T_{s}\right)$ and is constant.

The polynomial equation is given by:

$$
\begin{gathered}
s^{2}+2 \xi w_{n} s+w_{n}^{2}=0 \\
w_{n}=\sqrt{k \cdot k_{i}} \\
2 \xi w_{n}=20+k_{p} k \\
\xi=\frac{\left(20+k_{p} k\right)}{2 \sqrt{k \cdot k_{i}}}
\end{gathered}
$$

The parameters of the PI controller might be calculated as:

$$
\begin{gathered}
k_{p}=\frac{\left(2 \xi w_{n}-20\right)}{k} \\
k_{i}=\left[\frac{\left(w_{n} \cdot k_{p}\right)}{\left(2 \xi w_{n}-20\right)}\right]^{2}
\end{gathered}
$$

The close loop of the stator flux estimation with PI parameters is tested as shown in Fig. 5. The reference flux and 


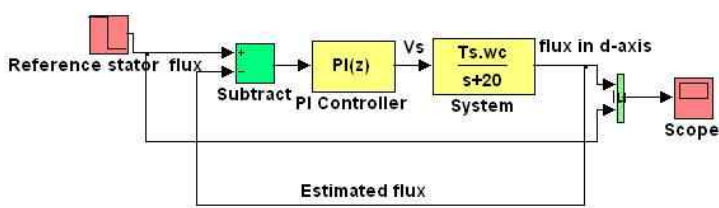

Fig. 5. Simulink model of close loop of stator flux estimation.

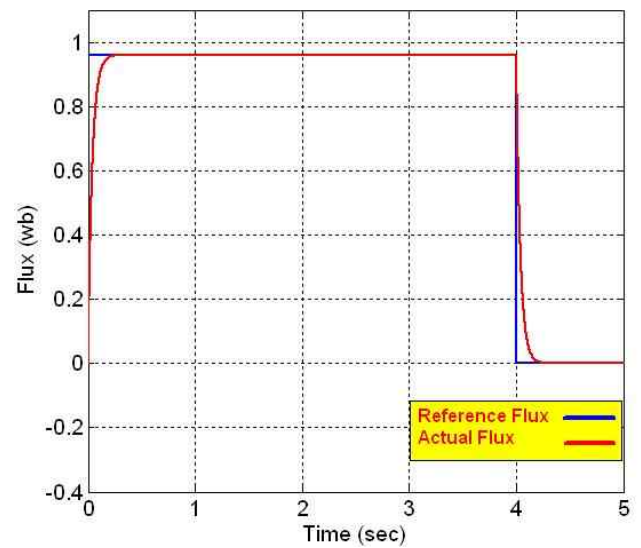

Fig. 6. Flux performance based on PI parameters.

sampling time are 0.96 and $50 \mu \mathrm{s}$, respectively. From Fig. 6, it can be seen that the quick response of the actual flux is achieved. It can also be seen that the flux tracks the reference well without steady state errors. This strongly confirms the optimal values of the PI parameters.

\section{FUZZY LOGIC CONTROLLER IN DTC-SVM}

Fuzzy logic control is the process of formulating the mapping from a given input to an output using fuzzy logic. It has some advantages such as the fact that it does not require an exact mathematical method. The torque reference is compared with the torque estimation and the error is the input to the fussy logic controller. These input values are the normalized value of the torque error that should remain between \pm 1 . The torque error is minimized by fuzzy logic to achieve a proper voltage in the quadrature reference frame $\left(V_{q s}\right)$ and a constant switching frequency. The proposed method for a fuzzy logic controller is shown in Fig.7. The classical PI torque and flux controller were replaced by two fuzzy logic controllers. On the other hand, the stator flux is compared with the stator flux estimation and the error is sent to the fuzzy logic controller which minimizes the error to reduce the total harmonic distortion of the stator current. The membership function of the FL-torque and the flux controller are shown in Fig.8 and Fig.9, respectively.

The rules of the fuzzy logic torque and flux controller are shown in Table I and II, respectively

From Fig.7, the relationship between the output of the FL flux controller $\left(V_{s d}\right)$ and the magnitude of the stator flux

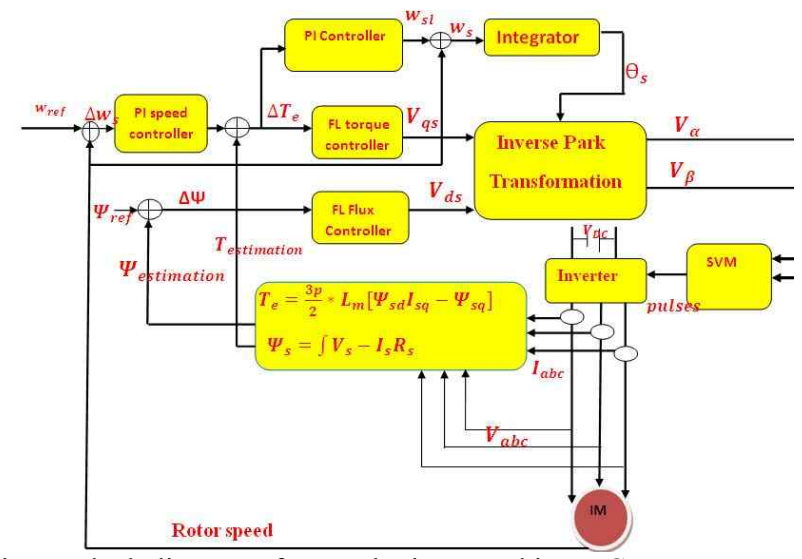

Fig. 7. Block diagram of Fuzzy logic control in DTC.

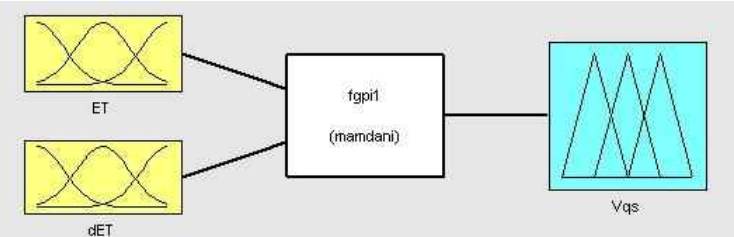

(a)

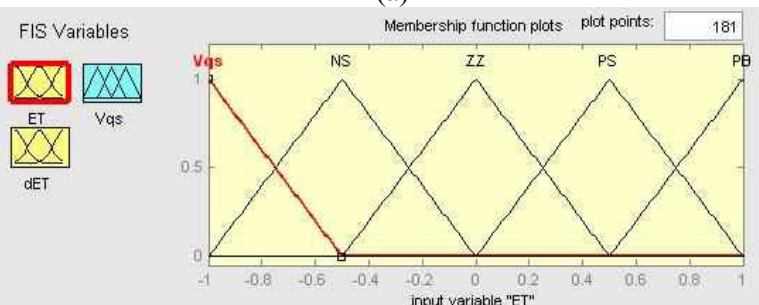

(b)

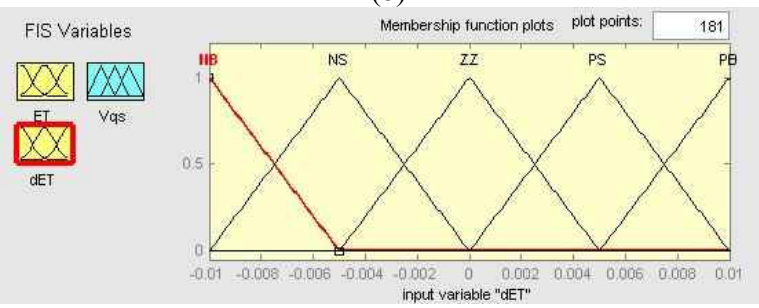

(c)

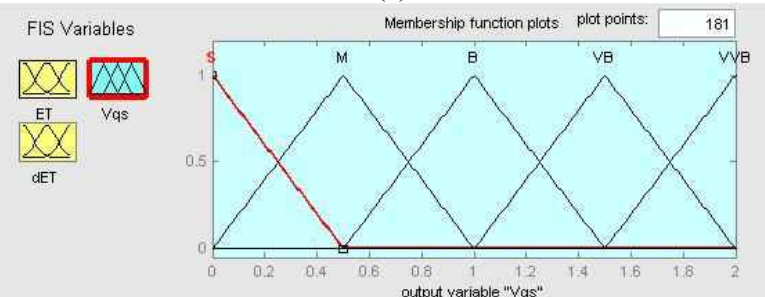

(d)

Fig. 8. Fuzzy logic torque controller. (a) Input- output of fuzzy logic torque controller. (b) Membership functions of torque error. (c) Membership functions of the change of torque error. (d) Membership functions of output voltage in q-reference frame.

estimation $\left(\Psi_{\text {est }}\right)$ can be expressed as shown below.

The output of the stator flux in the stator flux estimation is expressed as: 
TABLE I

Rules OF FuZzy LOGIC TORQue CONTROLleR

\begin{tabular}{|c|c|c|c|c|c|}
\hline ET/ & NB & NS & zz & PS & PB \\
\hline NB & s & s & M & $M$ & B \\
\hline NS & s & M & $M$ & B & VB \\
\hline Zz & M & M & B & VB & VB \\
\hline PS & M & B & VB & VB & VVB \\
\hline PB & B & VB & VB & VVB & VVB \\
\hline
\end{tabular}

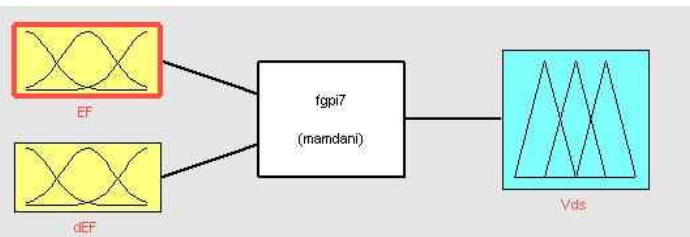

(a)

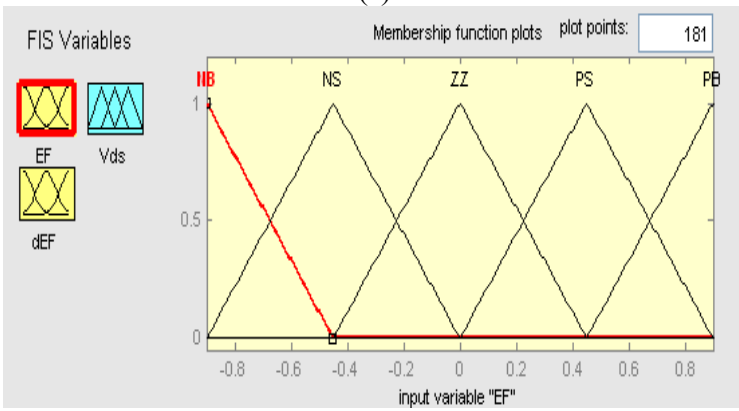

(b)

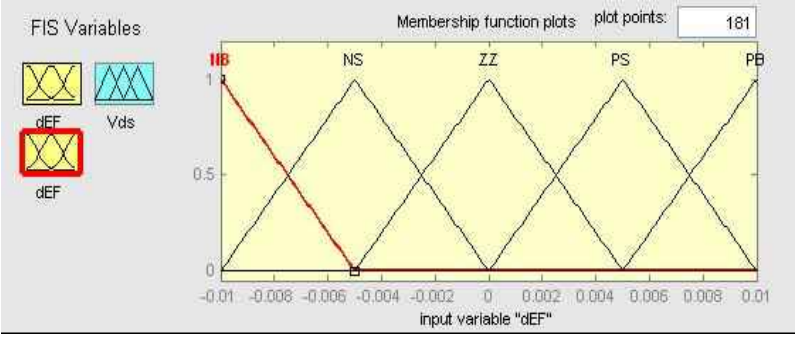

(c)

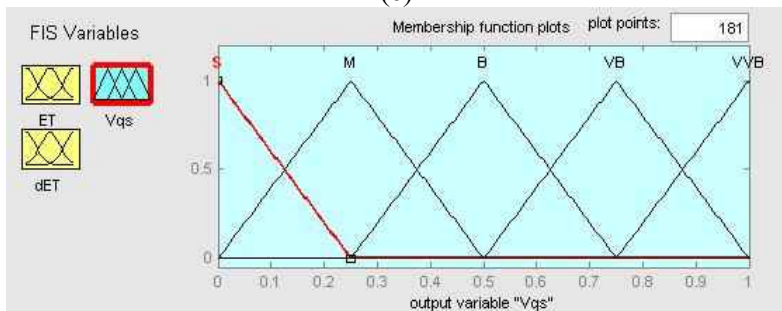

(d)

Fig. 9. Fuzzy logic flux controller. (a) Input- output of fuzzy logic flux controller. (b) Membership functions of flux error. (c)

Membership functions of the change of flux error. (d) Membership functions of output voltage in d-reference frame.

$$
\begin{gathered}
\Psi_{S}=\left|\Psi_{S}\right| e^{j \theta_{S}} \\
\Psi_{e s t}=\left|\Psi_{s}\right|
\end{gathered}
$$

TABLE II

\begin{tabular}{|c|c|c|c|c|c|}
\hline $\mathrm{EF} /$ & NB & NS & $\mathrm{zz}$ & PS & PB \\
\hline NB & s & $s$ & $\mathrm{M}$ & $M$ & B \\
\hline NS & $s$ & M & M & B & VB \\
\hline $\mathrm{zz}$ & M & M & B & VB & VB \\
\hline PS & M & B & VB & VB & VVB \\
\hline PB & B & VB & VB & VVB & VVB \\
\hline
\end{tabular}

Rules OF FuZzy LOGIC FluX CONTROLleR

$$
\begin{gathered}
\left|\Psi_{S}\right|=\mid \Psi_{S} e^{-j \theta_{S}} \\
\left|\Psi_{S}\right|=\mid \Psi_{S}\left(\cos \theta_{S}-j \sin \theta_{S}\right)
\end{gathered}
$$

By using the Laplace transform the following is obtained:

$$
\begin{gathered}
\left|\Psi_{S}\right|=\Psi_{S}\left[\frac{S}{S^{2}+\theta_{s}^{2}}-j \frac{\theta_{s}}{S^{2}+\theta_{s}^{2}}\right] \\
\theta_{S}=w_{S} \cdot T_{S} \cong 0 \\
\left|\Psi_{S}\right|=\Psi_{s}\left[\frac{1}{s}\right] \\
\Psi_{s}=\Psi_{s d}+j \Psi_{s q} \\
\left|\Psi_{S}\right|=\left(\Psi_{s d}+j \Psi_{s q}\right) \frac{1}{s}
\end{gathered}
$$

Separating the real and imaginary in equation (36) yields:

$$
\begin{gathered}
\left|\Psi_{s}\right|=\left(\Psi_{s d}\left[\frac{1}{s}\right]\right. \\
0=j \Psi_{s q\left[\frac{1}{s}\right]} \\
\Psi_{s d}=\left(V_{s d}-I_{s d} \cdot R_{s}\right) T_{s} \\
\Psi_{s d}=\left(V_{s d}-\frac{\Psi_{r d}}{L_{m}} \cdot R_{s}\right) \cdot T_{s} \\
\frac{\Psi_{r d}}{L_{m}} \cdot R_{s} \cdot T_{s} \cong 0
\end{gathered}
$$




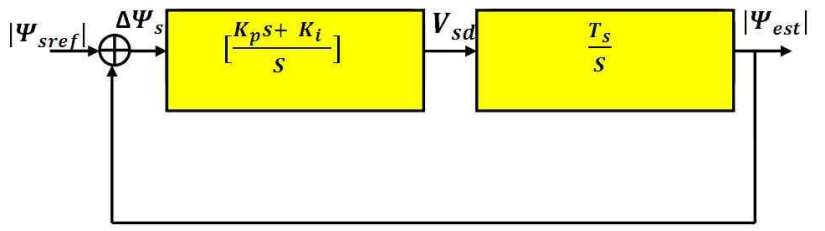

Fig. 10. Block diagram of the flux control loop.

TABLE III

INDUCTION MOTOR PARAMETERS

\begin{tabular}{|lll|}
\hline 3-phase & $2.2 \mathrm{KW}$ & $R_{s}=3.2 \Omega$ \\
$50 \mathrm{~Hz}$ & 4 -poles & $R_{r}=2.1 \Omega$ \\
$400 \mathrm{~V}$ & $5 \mathrm{~A}$ & $L_{s}=0.24 \mathrm{H}$ \\
$N_{r}=1450 \mathrm{rpm}$ & $L_{m}=0.2$ & $L_{r}=0.24 \mathrm{H}$ \\
\hline
\end{tabular}

$$
\left|\Psi_{S}\right| \cong \frac{V_{s d} \cdot T_{S}}{s}
$$

The relationship between the output of the FL flux controller $\left(V_{s d}\right)$ and the magnitude of the stator flux estimation $\left(\Psi_{\text {est }}\right)$ can be expressed as:

$$
\frac{\left|\Psi_{e s t}\right|}{V_{s d}}=\frac{T_{s}}{s}
$$

The close loop transfer function between the magnitude of the stator flux estimation $\left|\Psi_{\text {est }}\right|$ and the reference of the stator flux $\left|\Psi_{S(\text { ref })}\right|$ is:

$$
\frac{\left|\Psi_{\text {est }}\right|}{\left|\Psi_{s(\text { ref })}\right|}=\frac{k_{p} \cdot T_{s} s+T_{s} k_{i}}{s^{2}+k_{p} T_{s} s+T_{s} k_{i}}
$$

Fig. 10 shows a block diagram of the close loop between the reference of the stator flux and the magnitude of the stator flux estimation.

\section{Simulation RESUltS}

To verify the proposed scheme, a simulation has been carried out using MATLAB/SIMULINK. The stator flux and torque loop estimation of the drive were also designed and simulated. The proposed torque and flux fuzzy regulators are developed by using the fuzzy Toolbox. The parameters of the induction motor that are used in this simulation are shown in Table III. The effectiveness of the proposed SVM-DTC based on a fuzzy logic controller and a close loop of the stator flux

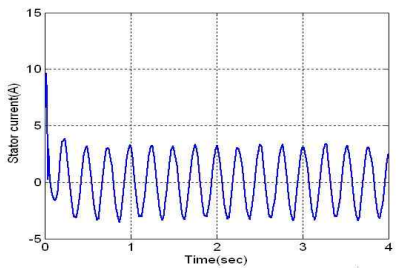

(a) Stator current.

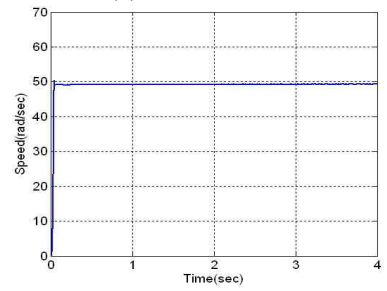

(c) Rotor speed.

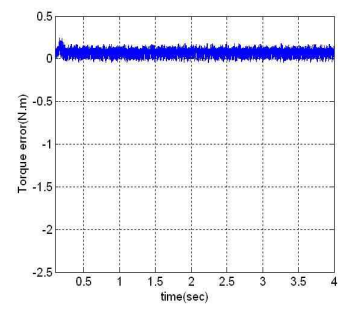

(e) Torque error.

Fig. 11. Results of proposed Method.

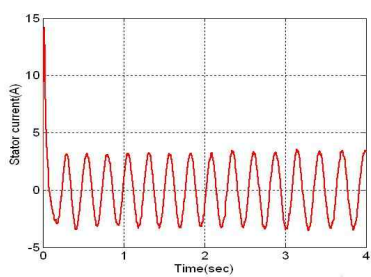

(a) Stator current.

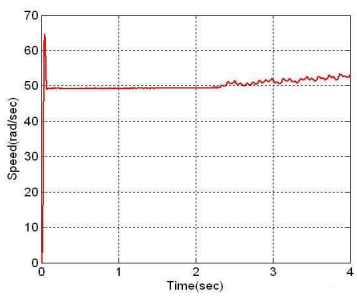

(c) Rotor speed.

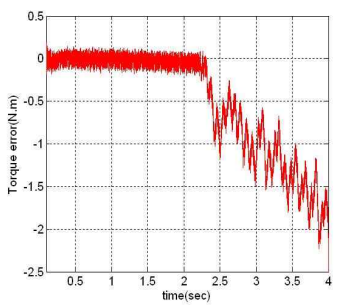

(j) Torque error.

Fig. 12. Results of SVM-DTC.

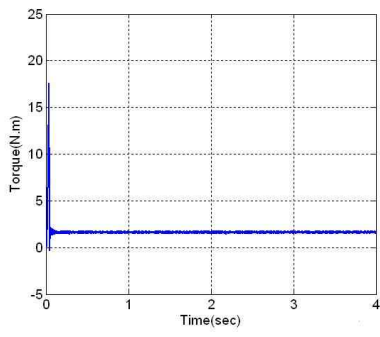

(b) Electromagnetic torque.

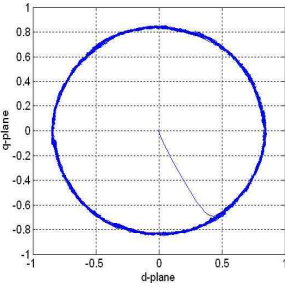

(d) Stator flux.

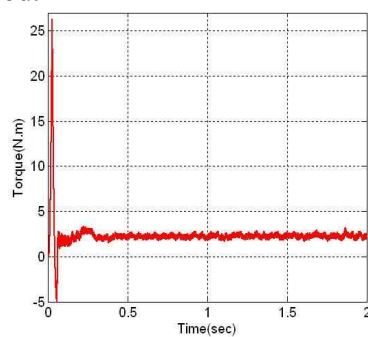

(b) Electromagnetic torque.

(d) Stator flux.

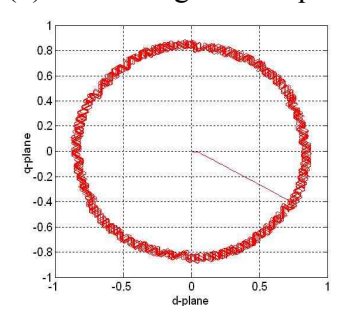


estimation scheme, whose block diagram is depicted in Fig.7, is evaluated through a comparative simulation study along with classical SVM-DTC.

The steady state responses of the classical SVM-DTC and the proposed SVM-DTC scheme under a very low speed (50 rad/sec under a full-load torque (14.5 N.m)) operating condition are illustrated in Fig.11 and Fig.12. It can be seen that the presented scheme delivers a much smoother steady state performance in terms of torque and rotor speed despite the slightly improved flux ripples. The steady state of the rotor speed in the proposed method is achieved within a minimal time of 0.2 second. However, in classical SVM-DTC, the rotor speed is achieved at the steady state after an over shoot equal to $15 \mathrm{rad} / \mathrm{sec}$, with high ripple after 2.2 seconds. In fact, the $27 \mathrm{~N} . \mathrm{m}$ torque over shoot is reduced to $14 \mathrm{~N} . \mathrm{m}$ and it is free from undershoot in the case of the proposed method. In addition, the torque ripple is reduced from 1 N.m to $0.3 \mathrm{~N} . \mathrm{m}$. The starting current is reduced from 14A to $10 \mathrm{~A}$ without any distortion and with a ripple free stator flux at the steady state. On the other hand, the torque error between the reference torque and the torque estimation in the proposed method is very low and equal to $0.2 \mathrm{~N} . \mathrm{m}$. As a result, a constant switching frequency is achieved. In contrast, the torque error in the SVM-DTC changes from 0.2 to $-2 \mathrm{~N} . \mathrm{m}$, which causes a variable switching frequency and degrades the performance of the control system.

From Fig. 13, it is obvious that the simulation results at a very low speed $(25 \mathrm{rad} / \mathrm{sec})$ demonstrate the feasibility and validity of the proposed DTC-SVM by effectively accelerating the system response, reducing the torque and the flux ripple, and improving the system performance. These robustly confirm the capability of the proposed method under very low speed operation.

\section{EXPERIMENTAL RESULTS}

The experimental setup of the DTC-SVM based on fuzzy logic control is represented by the block diagram shown in Fig.14 and the picture in Fig. 15. It consists of a DSP28335, 2 current sensors, a voltage sensor, a two level inverter and a gate drive. The three phase induction motor parameters are same as those introduced in Table III. Digital motor control blocks (DMC) are used to simulate the proposed algorithm due to their easy compilation from Simulink/Matlab to $\mathrm{C}++$ or $\mathrm{C}$ through the Texas Instruments F28335 DSP. The DTC-SVM fuzzy logic algorithm with a hardware interrupt is shown in Fig. 16.

In Fig. 16, the DTC-SVM fuzzy logic algorithm is triggered when the analogue to digital converter ADC finishes conversion. This guarantees that the DTC-SVM algorithm is synchronized with the PWM module. Fig.17 shows the algorithm control of the SVM based on the ADC. The block analogue to digital converter $\mathrm{ADC}$ is used to convert the analogue values to digital values and it stores the converted

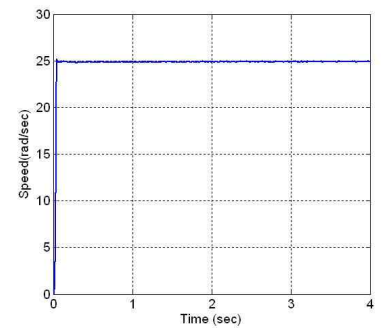

(a) Rotor speed.

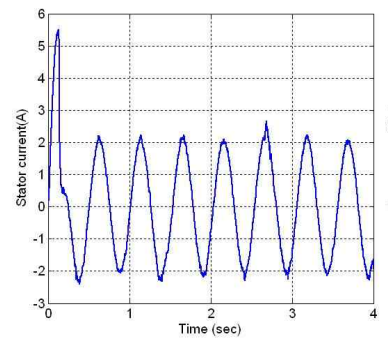

(c) Stator current.

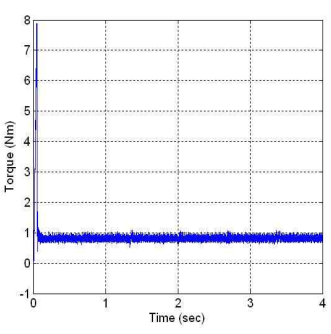

(b) Electromagnetic torque.

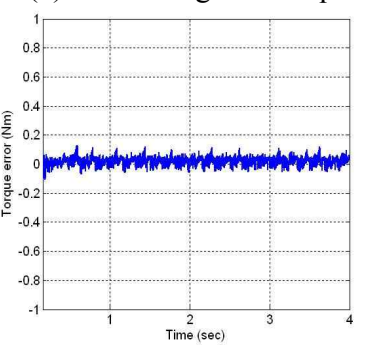

(d) Torque error.

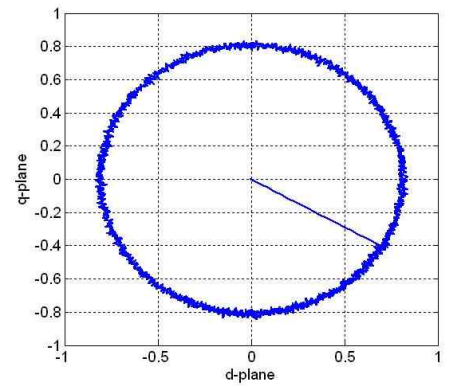

(e) Stator flux.

Fig. 13. Results of proposed method (at $25 \mathrm{rad} / \mathrm{sec}$ ).

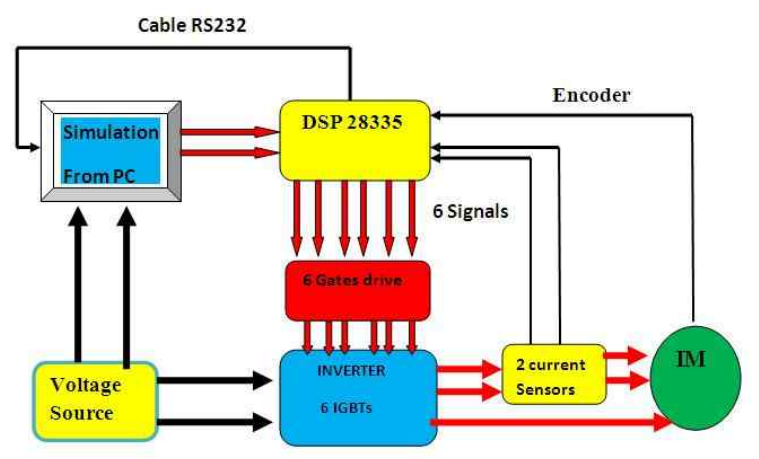

Fig. 14. Block diagram of hard ware implementation.

values in the result registers of the DSP28335. The currents $\left(I_{a} I_{b}\right)$ coming from the current sensors on phases A and B of the motor are connected to the ADCINAO and ADCNA1 of the DSP28335. On the other hand, the QEP decoder is used to translate signals from the encoder into an angle value that can be fed into the DTC algorithm by a connection to the output of the encoder to the ADCINA7 of the DSP28335. The DSP transmits the real data to the host side serial monitor receiver (SCI Receive) via the appropriate RS232 transceivers, as shown in Fig. 18. 


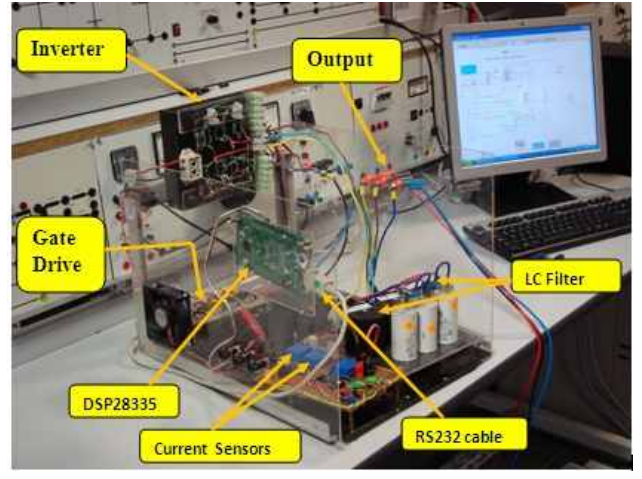

(a)

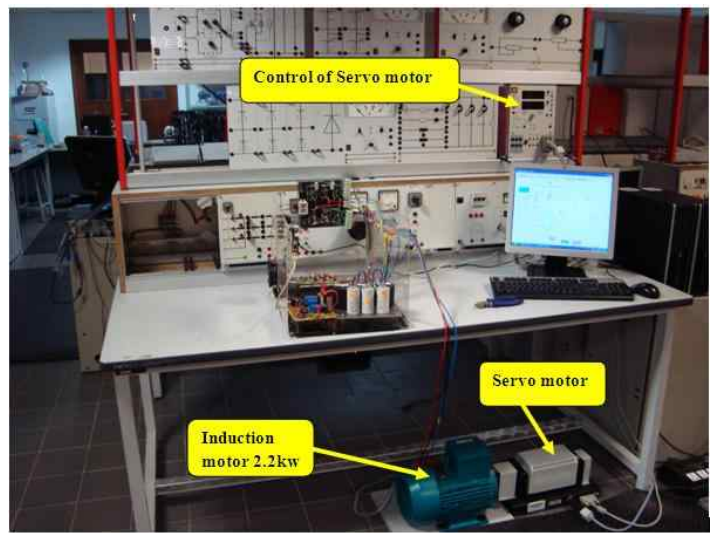

(b)

Fig. 15. Experimental set up (a) Circuit of induction motor drive. (b) Induction motor setup.

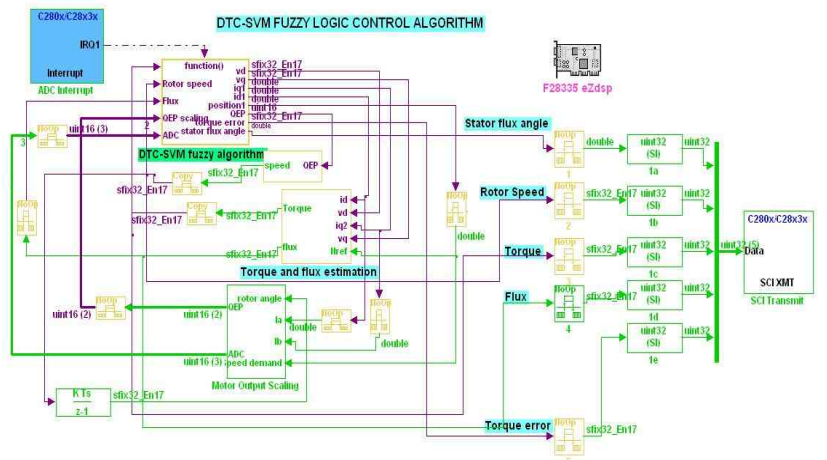

Fig. 16. DTC-SVM fuzzy logic algorithm with hardware Interrupt.

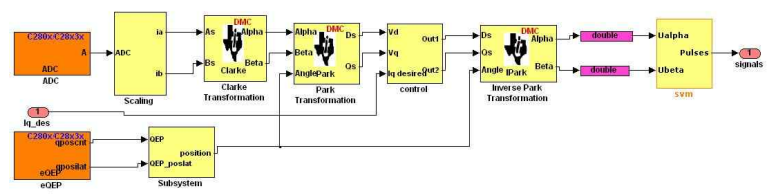

Fig. 17. Algorithm control of SVM based on ADC.

\section{A . At $100 \mathrm{Rad} / \mathrm{sec}$, load torque $6 \mathrm{Nm}$ (40\% of full load)}

Figures 19, 20, 21, and 22 show the transient and steady state responses of the proposed DTC-SVM fuzzy logic based on a close loop of the stator flux estimation for $6 \mathrm{Nm}(40 \%$ of the full load operation) at $100 \mathrm{rad} / \mathrm{sec}$. The experimental torque of the proposed method is illustrated in Fig. 19. The steady state of the experimental torque is almost $6 \mathrm{Nm}$ with a torque ripple of $1 \mathrm{Nm}$ as compared with the simulation results.

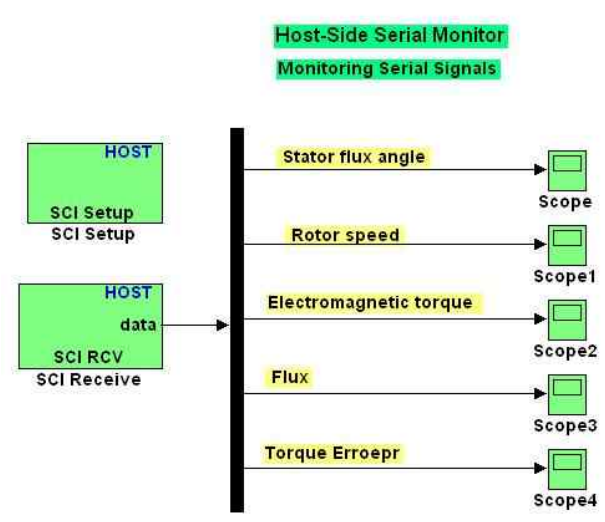

Fig. 18. Monitoring data.

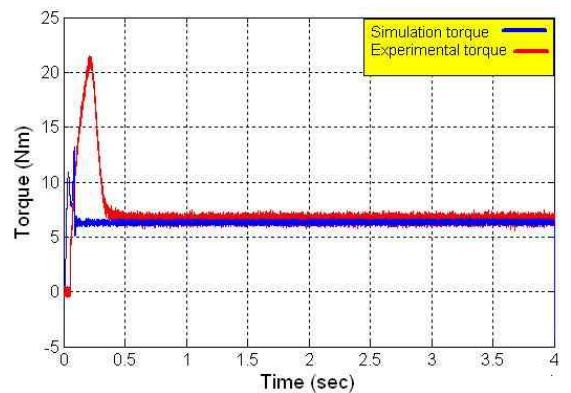

Fig. 19. Experimental and simulation comparison of torque.

From Fig. 20, the real speed of the proposed method reaches the rated value $(100 \mathrm{rad} / \mathrm{sec})$ after $0.2 \mathrm{sec}$ without oscillations but the response is slow when compared with the simulation speed. In Fig. 21, the steady state torque error for both the experimental and simulation results is zero after $0.4 \mathrm{sec}$.

Fig. 22 shows the response of the stator flux locus for the proposed method. It can be seen that the real stator flux locus of the proposed method is circular in shape and that it has a low ripple.

In Fig. 23, it can be seen that frequency of the stator flux angle is increased with increasing speed because it depends on both the slip angular frequency and the rotor angular frequency (rotor speed).

\section{CONCLUSIONS}

This paper has presented a modified Direct Torque Control space vector modulation based on fuzzy logic control and a close loop of the stator flux estimation for fed asynchronous motor drives using a constant switching frequency. The constant switching frequency is achieved by using fuzzy logic torque controller instead of a PI torque controller to diminish the torque error between the reference torque and the torque estimation. A fuzzy logic controller is designed to generate the torque component in the SVM-DTC. The total harmonic distortion of the stator current is reduced by using the fuzzy 


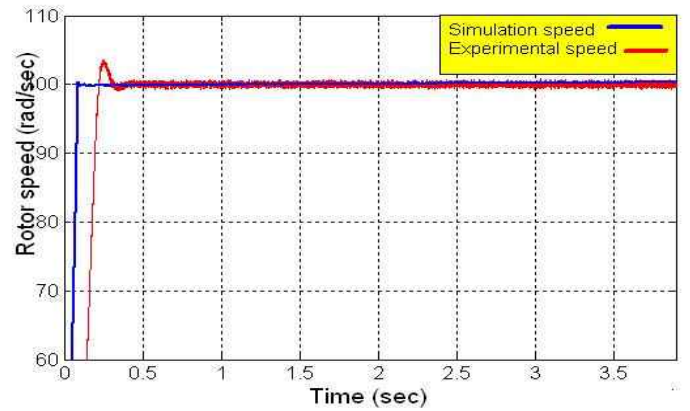

Fig. 20. Experimental and simulation comparison of speed.

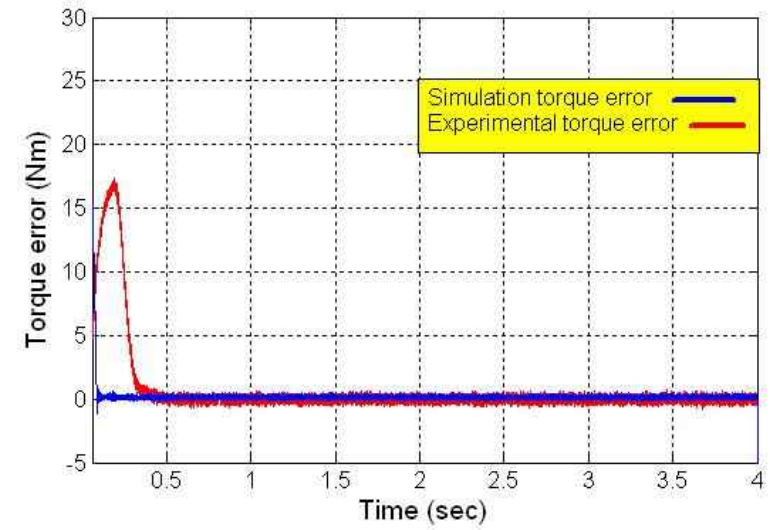

Fig. 21. Experimental and simulation comparison of torque error.

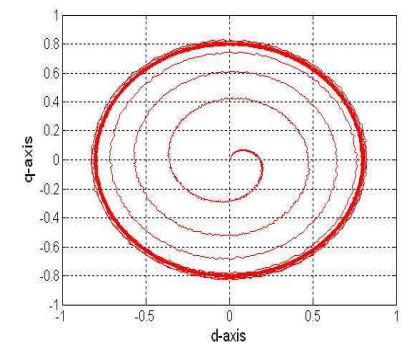

(a)

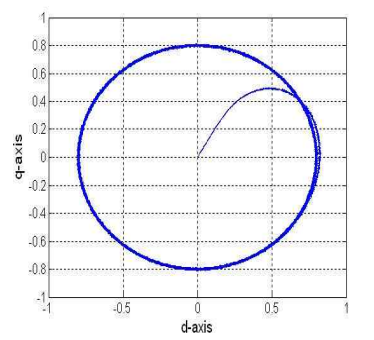

(b)
Fig. 22. Stator flux locus.(a). Eexperimental result. (b) simulation result.

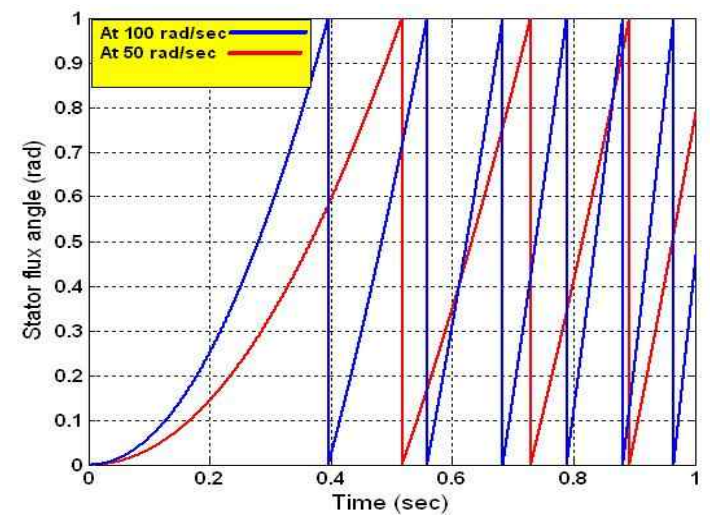

Fig. 23. Stator flux angle.

logic flux controller instead of a PI flux controller by minimizing the flux error between the reference of the stator flux and the stator flux estimation based on the control rules of the fuzzy logic controller. On the other hand, algorithm control of the close loop stator flux estimation is used to overcome the problems of de drift and saturation. The algorithm control is based on the close loop of the stator flux, a low pass filter and voltage correction. Experimental and simulation results verify that the proposed method achieves a reduction of the torque and flux ripples, minimizing the stator current distortion with the fast response of the rotor speed.

The fuzzy DTC-SVM with algorithm control of the stator flux estimation is an excellent solution for general-purpose asynchronous motor drives.

\section{REFERENCES}

[1] I. Takahashi and T. Noguchi, "A new quick-response and high efficiency control strategy of an induction machine," IEEE Trans. Ind. Applicat, Vol. 22, pp. 820-827.Oct,1986.

[2] T. Brahmananda Reddy, B. Kalyan Reddy, J. Amarnath, D. Subba Rayudu, and Md. Haseeb Khan, "Sensorless direct torque control of induction motor based on hybrid space vector pulsewidth modulation to reduce ripples and switching losses - A variable structure controller approach," IEEE Power India Conference, Apr. 2006.

[3] T. G. Habetler and D. M. Divan, "Control strategies for direct torque control using discrete pulse modulation," IEEE Trans. Ind. Appl, vol. 27, No. 5, pp.893-901, Sep./Oct. 1991.

[4] D. Casadei, G. Grandi, G. Serra, A. Tani, "Effects of flux and torque hysteresis band amplitude in direct torque control of induction machines," in 20th International Conference on Industrial Electronics Control and Instrumentation (IECON), Vol. 1, pp. 299-304, 1994.

[5] Y. S. Lai and J. H. Chen, "A new approach to direct torque control of induction motor drives for constant inverter switching frequency and torque ripple reduction," IEEE Trans. Energy Convers. Vol. 16, No. 3, pp.220-227, Sep. 2001.

[6] C. Lascu, I. Boldea, and F. Blaabjerg, "A modified direct torque control for induction motor sensorless drive," IEEE Trans. Ind. Applicat., Vol. 36, No. 1, pp. 122-130, Jan. 2000.

[7] S. A. Mir, M. E. Elbuluk, and D. S. Zinger, "Fuzzy implementation of direct self-control of induction machines," IEEE Trans. Ind. Appl. Vol. 30, No. 3, pp. 729-735, May/Jun. 1994.

[8] A. Arias, J. L. Romeral, E. Aldabas, and M. G. Jayne, "Fuzzy logic direct torque control," in Proceedings of the IEEE International Symposium on Industrial Electronics (ISIE), Vol. 1, pp. 253-258, 2000.

[9] L. Romeral, A. Arias, E. Aldabas, and Marcel G. Jayne, "Novel direct torque control (DTC) scheme with fuzzy adaptive torque-ripple reduction," IEEE Trans. Ind. Electron, Vol. 50, No. 3, pp.487-492, Jun.2003.

[10] J. Rodriguez, J. Pontt, S. Kouro, and P. Correa, "Direct torque control with imposed switching frequency in an 11-level cascaded inverter," IEEE Trans. Ind. Electron., Vol. 51, No. 4, pp. 827-833, Aug. 2004.

[11] K. Lee, S. H. Huh, and J. Y. Yoo, "Performance improvement of DTC for induction motor-fed by three-level inverter with an uncertainty observer using RBFN," IEEE Trans. Energy Convers., Vol. 20 , No. 2, pp. 
276-283, Jun. 2005

[12] Y. Sayouti, A. Abbou, M. Akherraz, and H. Mahmoudi, "Real-time DSP implementation of DTC neural network-based for induction motor drive," 5th IET International Conference on Power Electronics, Machines and Drives (PEMD 2010), pp. 1-5, Apr. 2010.

[13] M. Hajian, J. Soltani, G. A. Markadeh, and S. Hosseinnia, "Adaptive nonlinear direct torque control of sensorless im drives with efficiency optimization," IEEE Trans. Ind. Electron., Vol. 57, No. 3, pp. 975-985, Mar. 2010.

[14] G. H. B. Foo and M. F. Rahman, "Direct torque control of an IPM-synchronous motor drive at very low speed using a sliding-mode stator flux observer," IEEE Trans. Power Electron., Vol. 25, No. 4, pp-933-942, Apr. 2010.

[15] L. Jian, L. He, T. Wan, and C. Yu, "Efficiency-optimized space-vector-modulation direct torque control for AC motor drives," International Conference on Power Electronics and Drive Systems, pp. 348-353, Jan. 2010.

[16] E. S. Sergaki, "Motor flux minimization controller based on fuzzy logic control for DTC AC drives," XIX International Conference on Electrical Machines (ICEM), pp. 1-6, Sep. 2010.

[17] A. Draou and A. Miloudi, "A simplified speed controller for direct torque neuro fuzzy controlled induction machine drive based on a variable gain PI controller," 4th International Power Engineering and Optimization Conference (PEOCO), pp. 533-538, 2010.

[18] N. Rumzi Nik Idris, and A. Mohamed Yatim, "Direct torque control of induction machines with constant switching frequency and reduced torque ripple," IEEE Trans. Ind. Electron., Vol. 51, No. 4, pp. 758-767, Aug. 2004.

[19] B. Metidji, F. Tazrart, A. Azib, N. Taib, and T. Rekioua, "A new fuzzy direct torque control strategy for induction machine based on indirect matrix converter," International Journal of Research and Reviews in Computing Engineering, Vol. 1, No.1, pp. 18-22, Mar. 2011.

[20] C. B. Jabeur-Sedick and F. Fnaiech, "Fuzzy inference system based direct torque control," Proceedings of the 4th WSEAS International Conference on Non-linear Analysis, Non-linear Systems, pp. 103-108, 2005.

[21] A. Lokriti, Y. Zidani, and S. Doubabi, "Fuzzy logic control contribution to the direct torque and flux control of an induction machine," IEEE International Conference on multimedia Computing and Systems, pp. 1-6, Jul. 2011.

[22] S. M. Gadoue, D. Giaouris, and J. W. Finch "Modified direct torque control method for induction motor drives based on amplitude and angle control of stator flux," Electric Power Systems Research, Vol. 81, No. 10, pp. 1712-1718, Jul. 2008

[23] Y. S. Lai and J. C. Lin, "New hybrid fuzzy controller for direct torque control induction motor drives," IEEE Trans. Power Electron., Vol. 15, No. 5, pp. 1211-1215, Sep. 2003.

[24] L. Romeral, A. Arias, E. Aldabas, and M. G. Jayne "Novel direct torque control (DTC) scheme with fuzzy adaptive torque-ripple reduction," IEEE Trans. Ind. Electron., Vol. 50, No. 3, pp. 487-492, Jun. 2003.

[25] J. Zhang and M. F. Rahman "Analysis and design of a novel direct flux control scheme for induction machine," IEEE International Conference on Electric Machines and Drives, pp.426-430, May 2005.

[26] A. Abbou, Y. Sayouti, H. Mahmoudi, and M. Akherraz, "Fuzzy inference system based direct torque control," IEEE in Control and Automation,pp.1121-1126, Aug.
2010.

[27] J. Wang, H. Wang, X. L. Yuan, and T. H. Lu, "Novel intelligent direct torque control for permanent magnet synchronous motor drive," IEEE on Fuzzy System and Knowledge Discovery, pp. 226-230, Nov. 2008.

[28] N. Mahendran and G. Gurusamy, "Reduction of Torque and Speed Pulsation in Direct Torque control of Large Induction Motor Using Fuzzy Logic Controller," European Journal of Scientific Research, Vol. 48, No. 4, pp. 559-566, 2011.

[29] D. Casadei, G. Serra, and K. Tani, "Implementation of a direct torque control algorithm for induction motors based on discrete space vector modulation," IEEE Trans. Power Electron., Vol. 15, No. 4, pp. 769-777, Jul. 2000.

[30] Y. Zhang, J. Zhu, Z. Zhao, W. Xu, and D. G. Dorrell, "An improved direct torque control for three-level inverter-fed induction motor sensorless drive," IEEE Trans. Power Electron., Vol. 27, No. 3, pp. 1502-1513, Mar. 2012.

[31] Y. Kumsuwana, S. Premrudeepreechacharna, and H. A. Toliyat, "Modified direct torque control method for induction motor drives based on amplitude and angle control of stator flux," Electric Power Systems Research, pp. 1712-1718, Feb. 2008.

[32] A. Sivasubramanian and B. Jayanand, "Application of neural network structure in voltage vector selection of direct torque control induction moto," International Journal of mechanics and Thermodynamics, Vol. 1, No. 1, pp. 71-80, 2010.

[33] Z. Li .and Y. Ruan. "A novel control method based on wavelet neural networks for direct torque control in induction motor drives," International conference on Electrical machines and system, pp. 3967-3972, 2009.

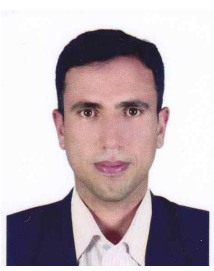

Hassan Farhan Rashag was born in Iraq in 1969. He received his B.S. and M.S. in Electrical Engineering (Electronics and Communications) from the University of Technology, Baghdad, Iraq, in 1992 and 1997, respectively. From 1992 to 2009, he was an Engineer in the Ministry of Industry. From 2009 to 2010, he was a Senior Lecturer and the Head of the Department of Quality at the Technical Institute of Babylon, Babylon, Iraq. He is currently pursuing his Ph.D. at the Universiti Tenaga Nasional, Selangor, Malaysia. His current research interests include control and power electronics.

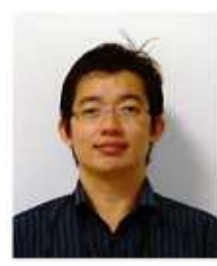

S. P. Koh received his B.S. (1st Class Hons.) in Electronics and Electrical Engineering, and his M.S. in Control and Automation from the University Putra Malaysia, Selangor, Malaysia, where he also received his Ph.D. in Artificial Intelligence and Machine Learning. His current research interests include machine intelligence and automation, lasers, advanced mechatronics and control systems. $\mathrm{He}$ is involved in a number of research projects, consultancy work and workshops, involving artificial intelligence, micro controllers and automation. 


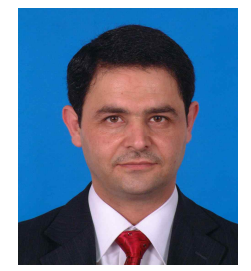

Ahmed N. Abdalla received his B.S. and M.S. in Electrical Power Engineering from the Technology University, Baghdad, Iraq, in 1997 and 2002, respectively. He received his $\mathrm{Ph} . D$. in Electrical Engineering from the Huazhong University of Science and Technology (HUST), Wuhan, China, in 2007. He is currently working as a staff member in the Faculty of Electrical and Electronic Engineering, University Malaysia Pahang, Kuantan, Malaysia. His current research interests include evolutionary computation, intelligent control, power-system automation, system identification and power electronics.

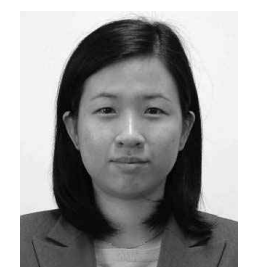

Nadia M. L. Tan (S'07) was born in Kuala Lumpur, Malaysia, in 1980. She received her B.S. (Hons.) in Electrical Engineering from the University of Sheffield, Sheffield, U.K., in 2002, and her M.S. in Electrical Engineering from the Universiti Tenaga Nasional, Kajang, Malaysia, in 2007. She received her Ph.D. from the Tokyo Institute of Technology, Tokyo, Japan, in 2010. Between 2003 and 2007, she was with Tenaga Nasional Berhad, Malaysia. Since May 2008, she has been a Lecturer in the Department of Electrical Power Engineering, Universiti Tenaga Nasional. Her current research interests include power conversion systems and bidirectional isolated dc-dc converters. Dr. Tan is a Graduate Member of the Institution of Engineers Malaysia (IEM).

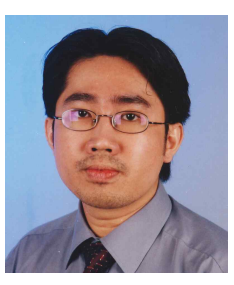

K. H. Chong received his B.S. (Hons) in Electronics and Electrical Engineering, his M.S. in Electronic Engineering and his $\mathrm{PhD}$ in Control Engineering from the Universiti Putra Malaysia, Selangor, Malaysia, in 2000, 2002 and 2007 respectively. His current research interests include artificial intelligence, evolutionary electronics, industrial process control, and automatic control systems. 